\title{
The role of ghrelin in patients with functional dyspepsia and its potential clinical relevance (Review)
}

\author{
TAKAKAZU YAGI ${ }^{1}$, AKIHIRO ASAKAWA $^{2}$, HIROTAKA UEDA $^{1}$, SHOUICHI MIYAWAKI $^{3}$ and AKIO INUI ${ }^{2}$ \\ ${ }^{1}$ Department of Orthodontics and Dentofacial Orthopedics, Medical and Dental Hospital, Kagoshima University, \\ Kagoshima 890-8544; Departments of ${ }^{2}$ Psychosomatic Internal Medicine and ${ }^{3}$ Orthodontics and Dentofacial Orthopedics, \\ Kagoshima University Graduate School of Medical and Dental Sciences, Kagoshima 890-8520, Japan
}

Received March 11, 2013; Accepted June 3, 2013

DOI: $10.3892 / \mathrm{ijmm} .2013 .1418$

\begin{abstract}
Functional dyspepsia (FD) is a functional gastrointestinal disorder (FGID). According to the Rome III consensus, FD is divided into 2 subgroups: epigastric pain syndrome (EPS) and postprandial distress syndrome (PDS). Although multiple mechanisms of FD pathogenesis have been suggested, its underlying etiology and pharmacological therapy remain unclear. Ghrelin is a gut-derived peptide found in the stomach. It plays a role in the regulation of gastric motility and appetite. The ghrelin gene encodes 3 molecular forms, acyl ghrelin, desacyl ghrelin and obestatin. Acyl ghrelin acts as an endogenous ligand for grow th hormone secretagogue receptor; furthermore, it is orexigenic, with effects on food intake, energy homeostasis and gastrointestinal motility. Des-acyl ghrelin exerts an opposite effect to acyl ghrelin. Obestatin exerts an inhibitory effect on the motor activity of the antrum and duodenum in fed animals. These peptides exert differential effects on gut motility and food intake. The therapeutic potential of ghrelin has attracted attention due to its varied bioactivities. Certain studies have shown that total ghrelin levels are significantly lower in patients with FD compared with healthy volunteers and that the acyl ghrelin levels of patients with FD are higher compared with healthy volunteers. However, a recent study demonstrated that acyl ghrelin levels in patients with PDS were lower compared with healthy volunteers; the association between FD and other ghrelin family gene products also remains unclear. Although certain studies have demonstrated the beneficial effects of acyl ghrelin administration and its agonist in patients with FD, only a few clinical reports exist.
\end{abstract}

Correspondence to: Dr Akihiro Asakawa, Department of Psychosomatic Internal Medicine, Kagoshima University Graduate School of Medical and Dental Sciences, 8-35-1 Sakuragaoka, Kagoshima 890-8520, Japan

E-mail: asakawa@m2.kufm.kagoshima-u.ac.jp

Key words: functional dyspepsia, acyl ghrelin, des-acyl ghrelin, obestatin, gastrointestinal motility
Further studies are required in order to examine the effects of ghrelin on FD.

\section{Contents}

1. Introduction

2. Functional dyspepsia

3. Effect of ghrelin on gastrointestinal motility via the braingut axis

4. Alterations in plasma ghrelin levels in patients with FD

5. Clinical potential of acyl ghrelin as a novel therapy for FD

6. Conclusion

\section{Introduction}

Functional dyspepsia (FD) is regarded as a functional gastrointestinal disorder (FGID), but it is a heterogeneous disorder (1). Although FD is divided into 2 major subgroups, epigastric pain syndrome (EPS) and postprandial distress syndrome (PDS) (2), up to half of the patients with FD present with an overlap of both PDS and EPS (3). Multiple pathogenic mechanisms have been proposed for FD, but its underlying etiology remains unclear, and its pharmacological therapy is also poorly understood.

It is known that hormones of the brain-gut axis are involved in the regulation of gut motility. Motilin, cholecystokinin (CCK), glucose-dependent insulinotropic peptide (GIP), glucagon like peptide-1 (GLP-1), peptide YY (PYY) and ghrelin are major gut hormones, and pharmacological therapy with certain hormones of the brain-gut axis are considered a novel treatment for FGID. In particular, ghrelin, which exhibits a variety of bioactivities, has attracted attention as a novel therapeutic drug.

Ghrelin, a 28-amino acid peptide hormone with structural resemblance to motilin, was originally discovered in the endocrine X/A-like cells of the gastric mucosa in rats and humans (4). The ghrelin gene consists of 4 exons and 3 introns, and ghrelin exists in 2 major molecular forms: acyl ghrelin, which has an n-octanoylated serine at position $3\left(\mathrm{Ser}^{3}\right)$ and des-acyl ghrelin, which lacks n-octanoylation (5-7). The third ghrelin gene product, obestatin, which is a 23 -amino acid 
peptide and was identified in the rat stomach, was found by comparative genomic analysis $(8,9)$. Ghrelin is also detectable in the hypothalamus, intestine, pituitary gland, placenta, salivary gland, as well as other tissues (4,8,10-12). Acylation at $\mathrm{Ser}^{3}$ is essential for the binding of ghrelin to growth hormone (GH) secretagogue-receptor (GHS-R)-1 and is catalyzed by ghrelin $O$-acyltransferase (GOAT) (13). Acyl ghrelin plays an important role in the stimulating the appetite, it regulates energy homeostasis and affects gastrointestinal motor activity, emptying $(9,14-16)$ and gastric acid secretion $(17,18)$. It also suppresses inflammation (8,9,18-21).

On the basis of this wide range of physiological functions, clinical trials of the efficacy of exogenous acyl ghrelin as a novel therapy have been performed in several disorders, including anorexia (22), cachexia $(23,24)$, FD (25) and malnutrition with gastroparesis (26). The aim of the present review was to provide an overview of the effects of ghrelin on FD, as well as to elucidate its pharmacological potential.

\section{Functional dyspepsia}

FD is characterized by one or more of 4 chronic symptoms, including epigastric pain or burning, postprandial fullness and early satiety in the absence of any known organic, systemic, or metabolic disease. According to the Rome III consensus, FD has been further subclassified into PDS and EPS (27). Although multiple pathogenic mechanisms are involved, patients with FD do not show evidence of organic disease in the upper digestive tract when examined by endoscopy or computed tomography (28). According to the Rome III criteria, FD symptoms must be present for at least 3 months prior to diagnosis, and a recent study revealed that the prevalence of FD in Japanese adults according to the Rome III criteria was $6.5 \%$ (29). However, the Rome III classification of FD is based on patient symptoms and the symptoms of patients with FD are not stable; thus, biochemical correlates of symptoms are extremely difficult to establish. According to the health insurance system in Japan, few dyspepsia patients wait 3 months prior to seeking medical care. Therefore, in the study by Miwa (28), it was estimated that the actual prevalence of FD in Japanese adults approaches 20-30\%.

FD refers to symptoms centered in the upper abdominal region. Some putative mechanisms have been suggested, involving biological interplay along the brain-gut axis according to the development of symptoms, including genetics, Helicobacter pylori (H. pylori) infection, visceral hypersensitivity, abnormal gastric acid secretion, abnormal gastroduodenal motility, autonomic/central nervous system (CNS) dysfunction, multiple psychosocial morbidities, depression and anxiety, as well as the effects of social stress (1,30-33).

It has previously been reported that $G$-protein $\beta 3$ subunit gene polymorphism is associated with FD (34). It has also been suggested that the serotonin transporter gene polymorphism, 5-hydroxytryptamine transporter gene linked polymorphic region (5-HTTLPR), affects susceptibility to PDS (35). These data suggest that the genetic factor may play a significant role in the development of FD. Residual inflammation following gastrointestinal infection is also known to increase the likelihood of developing FD, as demonstrated by a cohort study (36).
Association between $H$. pylori infection and $F D$. As regards the role of acute gastrointestinal (GI) infection and genetic susceptibility (37), certain studies in Western and Japanese populations have suggested that $H$. pylori infection is unlikely to influence the prevalence of FD $(38,39)$, and other studies have shown that $H$. pylori infection does not affect the overall prevalence of symptoms, gastric sensorimotor function, gastric sensitivity and the accommodation of the stomach to meals in patients with FD $(40,41)$. On the other hand, it has been reported that acid secretion, which is affected by infection with $H$. pylori, is associated with dyspeptic symptoms (42). A meta-analysis in China demonstrated that the association between $H$. pylori eradication and FD improvement is significant (43). A Cochrane review reported that the eradication of H. pylori in some patients with FD had a small but statistically significant long-term effect on symptom relief when compared with the placebo $(44,45)$. Moreover, a recent review also supported that $H$. pylori eradication improved symptoms in patients with FD, although certain studies only evaluated patients at 1 month (46). Thus, as regards $H$. pylori infection, opinion remains divided, although a recent consensus has suggested that if $H$. pylori infection is regarded as gastritis, an organic disease, then $H$. pylori associated dyspepsia should not be considered a functional disorder (47).

Association between stress and FD. Gastric hypersensitivity has been associated with symptoms of postprandial pain, belching and weight loss (48), although other studies have failed to demonstrate these associations $(49,50)$. A recent study suggested that gastric hypersensitivity is greater in patients with FD with a traumatic stress in early life than in the control patients with FD (33). Stress responses are mediated by stimulation of the hypothalamus-pituitary-adrenal (HPA) axis (51). In the hypothalamic paraventricular nucleus (PVN), stress induces the secretion of corticotropin-releasing factor (CRF), which stimulates the secretion of adrenocorticotropic hormone (ACTH) through the corticotrophs of the anterior pituitary (52). Moreover, ACTH induces the secretion of cortisol (53). The CRF system consists of 4 ligands: CRF, urocortin (UCN)-1, -2 and -3, and 2 G-protein-coupled receptors (GPCR), CRF-receptor 1 (CRF-R1) and CRF-R2, as well as a secreted CRF binding protein (CRF-BP) $(54,55)$. The CRF-R1 system regulates anxiety via the HPA axis. CRF-R2 is involved in regulation of upper GI motility and CRF-R1 is involved in regulation of colonic motility (56-58). A history of abuse, both physical and sexual, has been associated with alterations in gastric sensorimotor function and impaired gastric empting in patients with FD (33). In animal experiments, it has been shown that maternal separation during the neonatal period is a powerful stress inducer that results in increased visceral sensation and plasma corticosterone levels (59). When repeated doses of strong electric shock were administered to neonatal mice, their hippocampal glial cells became necrotic and this incuded the migration of stem cells from the bone marrow to the hippocampus (60). Thus, traumatic stress and noxious stimuli in early life may lead to serious neuroplastic alterations in the HPA and in the descending pathways that modulate spinal nociceptive transmission, as well as in the CNS (61). Moreover, such neuroplastic changes can occur in spinal ascending neurons receiving synaptic input from the 


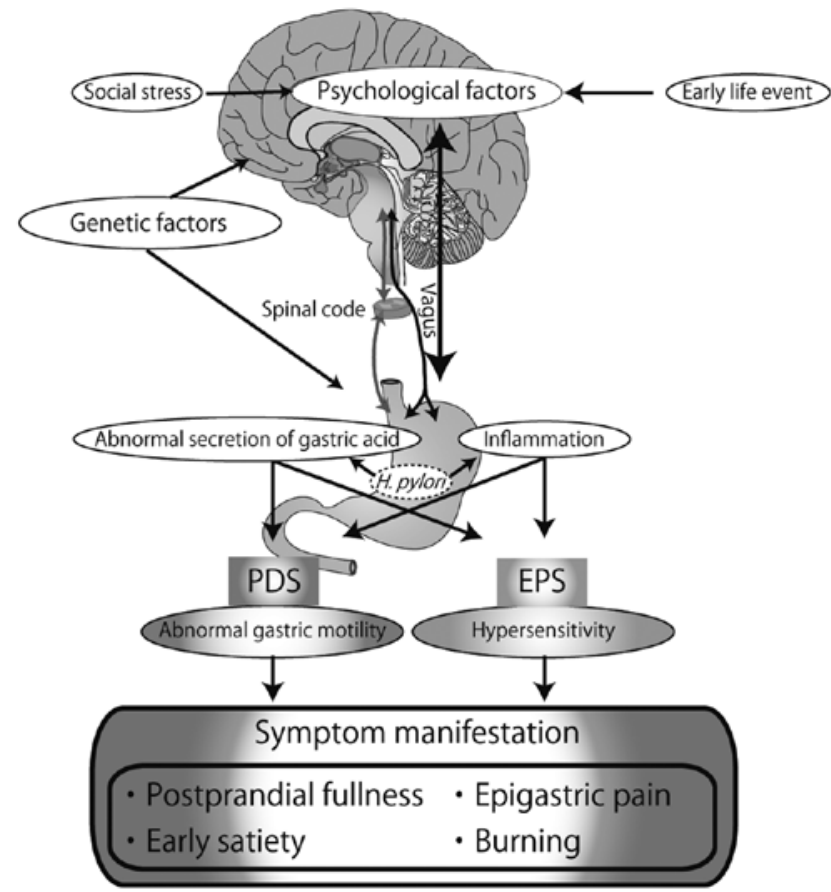

Figure 1. Schematic illustration model of the suggested pathogenesis of functional dyspepsia (FD). PDS, postprandial distress syndrome; EPS, epigastric pain syndrome.

gastrointestinal organs (central sensitization) and in the brain (supraspinal pain modulation), but also in primary sensory afferent terminals (peripheral sensitization) (61). These alterations in the processing of sensory information are considered mechanisms of visceral hypersensitivity (61).

Although several factors have been implicated in the pathophysiology of FD, the underlying pathogenesis of FD remains unclear and warrants further investigation. A schematic model illustrating the suggested pathogeneis of FD is presented in Fig. 1.

\section{Effect of ghrelin on gastrointestinal motility via the brain- gut axis}

The derangement of plasma ghrelin family protein levels may affect gut motility regulation in patients with FD. Fasting total ghrelin levels may assist with the evaluation of the pathophysiology of FD. In addition, acyl ghrelin levels have been associated with gastric emptying $(62,63)$, and delayed gastric emptying has been associated with postprandial fullness and severe early satiety in patients with FD (64). In this section, we elucidate the neural transmission mechanisms of each of the 3 ghrelin gene products as they act on gastrointestinal or gastroduodenal motility.

Acyl ghrelin. Acyl ghrelin has various functions in the stimulation of GH secretion through GHS-R and in the regulation of food intake, energy homeostasis, insulin secretion, as well as glucose and lipid metabolism. Acyl ghrelin functions in the gastrointestinal system, the cardiovascular system and the immune system (8). Acyl ghrelin is the only ghrelin hormone with an orexigenic effect following peripheral administration (65). Acyl ghrelin induces the gastric phase III of the migrating motor complex and the gastric emptying of solids in healthy human volunteers (15). Studies conducting experiments on rats in the fed state, have shown that the intracerebroventricular (ICV) and intravenous (IV) administration of acyl ghrelin induces phase III-like contractions of the antrum and the duodenum in the fasted state and increases the percentage motor index (\%MI) of the antrum (66). This fasted motor activity of the gastrointestinal tract has been considered to be a mechanical cleansing of the stomach and the intestines in preparation for the next meal. Truncal vagotomy blocked the effects of the ICV administration of acyl ghrelin on antral and duodenal motility (66). Therefore, a vagal pathway may mediate the influence of centrally administrated ghrelin on gastroduodenal motility. Acyl ghrelin induces fasted motor activity in the gastrointestinal tract by the activation of neuropeptide Y (NPY) neurons in the hypothalamus via both central pathways and a vago-vagal reflex (12). The effects of the IV administration of acyl ghrelin were not altered by the ICV administration of GHS-R antagonist in a vagotomized rat model. Acyl ghrelin acts via the GHS-R of vagal afferent fibers in the stomach (14) that transmit the signal to the nucleus of the solitary tract (NTS). The information from the NTS is projected to the arcuate nucleus (ARC) of the hypothalamus, where the NPY neurons are activated. The NPY Y2 and/or $\mathrm{Y} 4$ receptors in the CNS may be involved in upper gastrointestinal motility as $\mathrm{Y} 2$ and $\mathrm{Y} 4$ receptor agonists can induce phase III-like contractions in the duodenum when administered to animals in the fed state $(67,68)$. The signal from the ARC is finally transmitted to the dorsal motor nucleus of the vagus nerve [dorsal vagal complex (DVC)] and via vagal efferent fibers, and fasted motor activity is induced in the gut (69). Evidence suggests that acyl ghrelin may potentially be used as an exogenous prokinetic agent for the treatment of slow transit in the upper gastrointestinal tract (70).

Des-acyl ghrelin. Des-acyl ghrelin exerts opposite effects to acyl ghrelin on food intake and gastrointestinal motility (71). Two separate studies have shown that transgenic mice with an overexpression of des-acyl ghrelin exhibited a decrease in body weight $(71,72)$. The intracisternal (IC) and peripheral administration of des-acyl ghrelin have been shown to significantly decrease food intake in food-deprived mice and delay gastric emptying $(73,74)$, and des-acyl ghrelin has been shown to inhibit the orexigenic effect of acyl ghrelin (75). Moreover, des-acyl ghrelin abolishes the effects of acyl ghrelin on the secretion of pancreatic hormone (76).

The ICV and IV administration of des-acyl ghrelin has been shown to disrupt fasted motility in the antrum but does not alter the fed duodenum in conscious rats, and does not alter fed motor activity in either the antrum or the duodenum (74). The IV administration of des-acyl ghrelin increases neuronal c-fos expression in the ARC and in the PVN of the hypothalamus, but not in the NTS. It has been suggested that des-acyl ghrelin is involved in the regulation of motor activity in the stomach and crosses the blood-brain barrier (BBB) (77), but not through the activation of vagal afferent pathways (71).

Changes in gastric motility induced by the IV administration of des-acyl ghrelin are antagonized by the ICV administration of a selective CRF-R2 antagonist, but are not affected by CRF-R1 antagonist (74). It has been suggested 


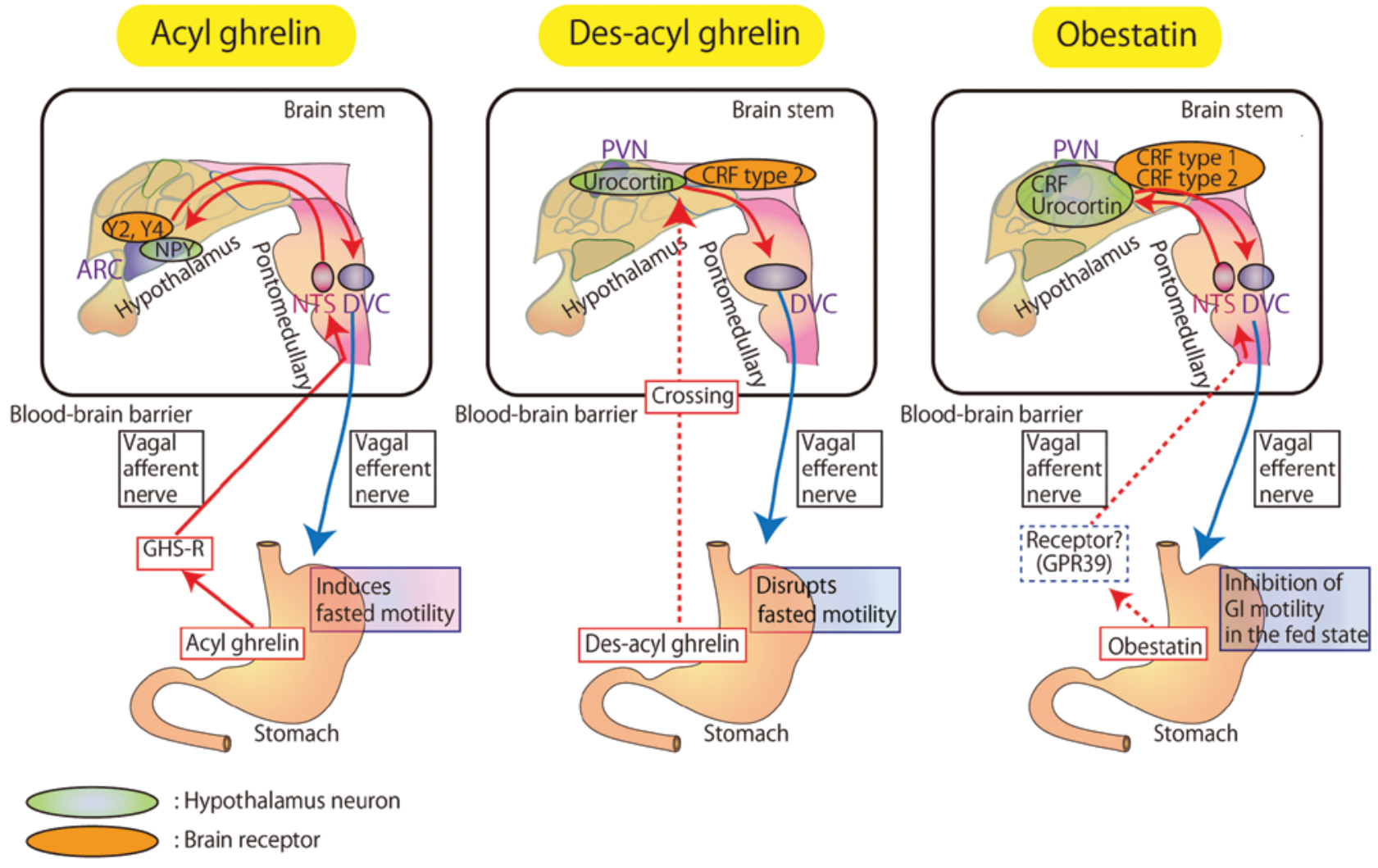

Figure 2. Effects of acyl ghrelin, des-acyl ghrelin, and obestatin via the brain-gut axis. Acyl ghrelin affects the growth hormone secretagogue-receptor (GHS-R) in vagal afferent nerve fibers in the stomach, which transmits the signal to the nucleus of the solitary tract (NTS). The signal from the NTS is activated by neuropeptide Y (NPY) neurons projected on the arcuate nucleus (ARC) of the hypothalamus. This signal is finally transmitted to the dorsal vagal complex (DVC) via vagal efferent fibers, and fasted motility is induced in the stomach. Des-acyl ghrelin directly activates neurons in the paraventricular nucleus (PVN) through the blood-brain barrier (BBB). This signal is transmitted to the DVC via the corticotropin-releasing factor (CRF) type 2 receptor, which may exert inhibitory effects on antral motility. Des-acyl ghrelin may disrupt fasted motility in the antrum through vagal efferent signaling in the DVC. Obestatin may act at least in part on GPR39 receptors in vagal afferent nerve fibers in the stomach that transmit this signal to the NTS. The signal from the NTS is activated and projected to the CRF and urocortin neurons on the PVN of the hypothalamus. This signal is transmitted to the DVC via CRF type 1 and 2 receptors. Finally, this signal may inhibit motor activity in the antrum and duodenum. The dotted line shows hypothetical correlations.

that des-acyl ghrelin directly activates neurons in the PVN and exerts inhibitory effects on antral motility via CRF-R2, but not CRF-R1 (74). CRF and the endogenous CRF receptor ligand, UCN, are feeding-inhibitory peptides localized at the PVN in the hypothalamus (78). UCN binds both CRF-R1 and CRF-R2. CRF-R2 is involved in stress-induced alterations in GI function (79). The ICV and IV administration of UCN has been shown to disrupt fasted motor activity in both antrum and duodenum, which show fed-like motor patterns (80). Therefore, des-acyl ghrelin may effect the stress-induced alteration of GI function.

Obestatin. Although obestatin was initially reported to be an endogenous ligand for the orphan $\mathrm{G}$ protein coupled receptor GPR39 (81), a number of studies have reported the non-specific binding of obestatin to various types of GPR39-expressing cells (82-84). In contrast to des-acyl ghrelin, the effects of obestatin on food intake are controversial $(71,74,85,86)$. The IV administration of obestatin decreases the \% MI in the antrum and prolongs the time before the return of fasted motility in the duodenum (87); obestatin also inhibits gastroduodenal motility in the fed state but not in the fasted state of conscious rats (87). The IV administration of obestatin has been shown to induce c-fos expression in the PVN of the hypothalamus, and immunofluorescence overlap staining has shown that PVN neurons containing CRF and UCN-2 are activated by the IV administration of obestatin (87). The inhibitory effect of the IV administration of obestatin on the motor activities in the antrum and duodenum is blocked by the ICV administration of CRF-R1 and CRF-R2 antagonists (87). Treatment with capsaicin has been shown to block the effects of obestatin on duodenal motility but not on antral motility (87). It has been shown that obestatin fails to antagonize the ability of acyl ghrelin to stimulate gastroduodenal motility (87). These results suggest that obestatin inhibits motor activity in the antrum and duodenum in the fed state and that both CRF-R1 and CRF-R2 receptors in the brain may be involved in the effects of obestatin on gastroduodenal motility. Moreover, vagal afferent pathways may be partially, but not entirely, involved (87).

The distinct effects of each of the 3 ghrelin gene products on gastrointestinal motility via the brain-gut axis are summarized in Fig. 2.

\section{Alterations in plasma ghrelin levels of patients with FD}

Two studies found that fasting total ghrelin levels were significantly lower in patients with FD compared with healthy volunteers $(63,88)$. Furthermore, these studies showed a signifi- 
cant decrease in the total ghrelin concentration that was evident postprandially in the controls but was absent in the patients with FD $(63,88)$. Nishizawa et al (89) showed that the total ghrelin levels in patients with FD categorized by the gastrointestinal symptom rating scale (GSRS) score positively correlated with the indigestion scores.

Two independent studies also demonstrated that plasma acyl ghrelin levels correlated with a subjective symptom score in female patients with FD $(89,90)$, and Nishizawa et al (89) further demonstrated that plasma acyl ghrelin levels were significantly higher in patients with FD compared with healthy volunteers. However, the study by Shinomiya et al (90) indicated that plasma acyl ghrelin levels were not significantly different between patients with FD and the controls, and another recent study indicated that plasma acyl ghrelin levels were significantly lower in patients with PDS compared with healthy volunteers, and the $\mathrm{T}_{\max }$ value, which is a marker of gastric emptying using a ${ }^{13} \mathrm{C}$ acetate breath test, was significantly higher in patients with PDS compared with healthy volunteers (62). Moreover, this study demonstrated that only patients with PDS showed a significant inverse correlation between plasma acyl ghrelin levels and $\mathrm{T}_{\max }$ values (62).

Although the results presented in the study by Kim et al (91) leave room for doubt as they focused only on 2 patients, the fasting plasma acyl ghrelin levels of the 2 patients with EPS were lower than the postprandial plasma acyl ghrelin levels. It is important to gather clinical data on patients with EPS as no general statement can be obtained from this study.

Takamori et al (88) reported that fasting des-acyl ghrelin levels were significantly lower in patients with FD compared with the controls, but Shinomiya et al (90) showed that desacyl ghrelin levels were not significantly different between patients with FD and the controls.

It has been reported that the ratio of acyl ghrelin to desacyl ghrelin (A/D ratio) also positively correlates with acyl ghrelin levels between patients with FD and the controls (90). Takamori et al (88) also suggested that A/D ghrelin ratios were significantly higher in patients with FD compared with the controls. Therefore, the A/D ratio may be an important signal for the evaluation of the pathophysiology of FD. However, the role of this ratio in clinical studies has not yet been established. Further mechanistic studies are required.

Studies that have assessed total ghrelin, acyl ghrelin and des-acyl ghrelin levels in patients with FD have produced conflicting results, as patients with FD present with a variety of symptoms. This variability may contribute to the different results in each study. As a result, there may be little evidence of a clearly defined role of ghrelin in FD. However, since acyl ghrelin affects gastrointestinal motor activity and emptying $(9,16)$, acyl ghrelin may be more closely associated with PDS than EPS. Similarly, other forms of ghrelin may also be associated with FD. Therefore, it is important that patients are divided into groups based on their symptoms when evaluating the role of ghrelin in FD. The association between ghrelin and FD is summarized in Table I.

\section{Clinical potential of acyl ghrelin as a novel therapy for FD}

Although few clinical reports are available on the administration of acyl ghrelin to patients with FD (25), it is anticipated that acyl ghrelin may be effective in relieving the symptoms of FD. As previously reported, repeated IV infusions of acyl ghrelin $(3 \mu \mathrm{g} / \mathrm{kg})$ twice a day to patients with FD for 2 weeks tends to increase daily food intake by approximately $30 \%$, and hunger sensation has been shown to be significantly enhanced at the end of this course of therapy (25). Increased food intake was maintained even 1 week following the termination of treatment. In addition, ulimorelin (TZP-101), which is an acyl ghrelin receptor agonist, has been shown to relieve upper gastrointestinal symptoms and accelerate gastric emptying in diabetic patients with gastroparesis in a randomized clinical trial (26). These results demonstrate the therapeutic potential of acyl ghrelin, including its agonists or antagonists.

Similarly, serotonin [5-hydroxytryptamine (5-HT)] released from enterochromaffin cells of the duodenal mucosa mediates intestinal phase III-like contractions via 5-HT4 receptors in conscious rats (92). A randomized, double-blinded, placebocontrolled, crossover study revealed that the 5-HT1A receptor agonist, buspirone, significantly reduced the overall severity of symptoms of FD and the individual symptoms of postprandial fullness, early satiation and upper abdominal bloating. A 5-HT1A receptor agonist did not alter the rate of gastric emptying of solids or the sensitivity to gastric distention, but significantly increased gastric accommodation, whereas gastric emptying of liquids was delayed (93). An experimental study on conscious rats showed that mosapride citrate (mosapride), which is a prokinetic agent with 5-HT4 receptor agonistic activity, inhibited gastric distension-induced visceromotor response (VMR) along with blockage of 5-HT3 receptors by a mosapride metabolite $(94,95)$. In addition, a recent clinical trial showed that the orexigenic effect of rikkunshito, a traditional Japanese medicine, is involved in the stimulation of acyl ghrelin secretion by blocking the $5-\mathrm{HT} 2 \mathrm{~B} / 2 \mathrm{C}$ receptor pathway and enhancing GHS-R activity (96); another recent randomized controlled trial showed that the administration of rikkunshito to patients with FD for 4 weeks improved upper gastrointestinal symptoms, which was accompanied by an increase in the levels of acyl ghrelin (97). Thus, rikkunshito may be another therapeutic agent, leading to the stimulation of acyl ghrelin secretion by inhibiting the effects of 5-HT in patients with FD. It has been shown that the oral administration of rikkunshito enhances the plasma levels of acyl-ghrelin without exerting significant effects on the plasma levels of desacyl ghrelin, leading to an increase in the A/D ratio in rats (98). Furthermore, in a study on humans, the plasma levels of acylghrelin and the A/D ratio significantly increased following the administration of rikkunshito, whereas the plasma levels of des-acyl ghrelin showed a decreasing trend (99).

These results support the therapeutic potential of acyl ghrelin in patients with FD. However, the long-term effects and side-effects of peptide hormone therapies have not yet been elucidated. Thus, further mechanistic studies are required to confirm the therapeutic potential of acyl ghrelin in the treatment of FD.

\section{Conclusion}

In conclusion, in our review, we summarize the association between ghrelin and FD. FD involves abnormal gastric motility and visceral hypersensitivity, as well as multiple psychiatric 


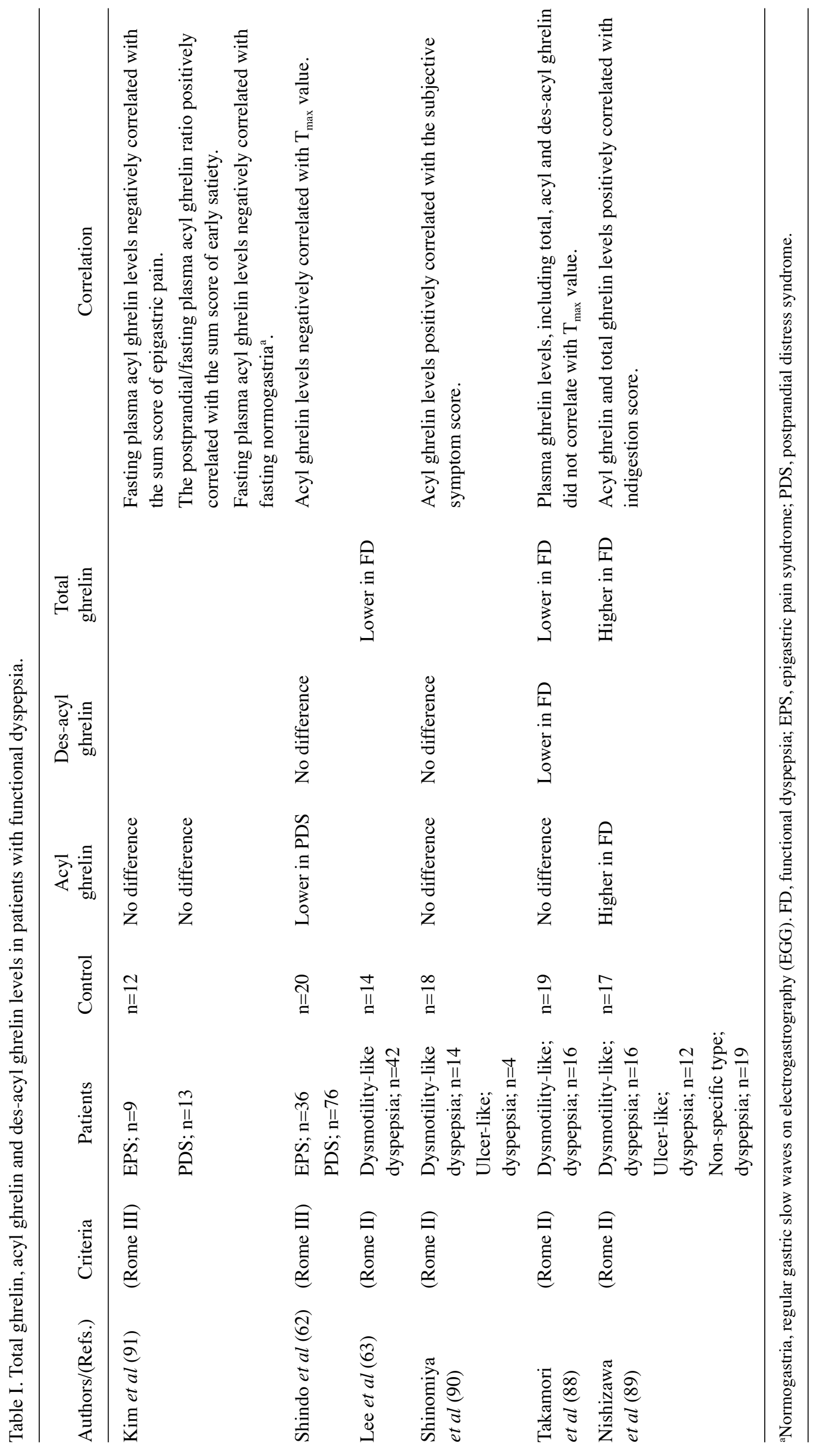


and individual factors. Ghrelin is a novel gastric hormone that is recognized as a mediator of $\mathrm{GH}$ release. Our review presents the various physiological functions of ghrelin, that have been discovered over the past decade. In addition, the data presented in this review indicate that acyl ghrelin plays a role in the regulation of food intake and gut motility. Therefore, acyl ghrelin may contribute to the improvement of FD symptoms. Future studies on the clinical application of acyl ghrelin in patients with FD are required to fully elucidate its role in FD.

\section{Acknowledgements}

This review was supported by the Japan Society for the Promotion of Science (JSPS) KAKENHI grant no. 24593103 and 24390464.

\section{References}

1. Tack J, Talley NJ, Camilleri M, et al: Functional gastroduodenal disorders. Gastroenterology 130: 1466-1479, 2006.

2. Geeraerts B and Tack J: Functional dyspepsia: past, present, and future. J Gastroenterol 43: 251-255, 2008.

3. Tack $\mathbf{J}$ and Talley NJ: Gastroduodenal disorders. Am J Gastroenterol 105: 757-763, 2010.

4. Kojima M, Hosoda H, Date Y, Nakazato M, Matsuo H and Kangawa K: Ghrelin is a growth-hormone-releasing acylated peptide from stomach. Nature 402: 656-660, 1999.

5. Matsumoto M, Kitajima Y, Iwanami T, et al: Structural similarity of ghrelin derivatives to peptidyl growth hormone secretagogues. Biochem Biophys Res Commun 284: 655-659, 2001

6. Tanaka M, Hayashida Y, Iguchi T, Nakao N, Nakai N and Nakashima K: Organization of the mouse ghrelin gene and promoter: occurrence of a short noncoding first exon. Endocrinology 142: 3697-3700, 2001.

7. Hosoda H, Kojima M, Matsuo H and Kangawa K: Ghrelin and des-acyl ghrelin: two major forms of rat ghrelin peptide in gastrointestinal tissue. Biochem Biophys Res Commun 279: 909-913, 2000.

8. Chen CY, Asakawa A, Fujimiya M, Lee SD and Inui A: Ghrelin gene products and the regulation of food intake and gut motility. Pharmacol Rev 61: 430-481, 2009.

9. Asakawa A, Inui A, Kaga T, et al: Ghrelin is an appetite-stimulatory signal from stomach with structural resemblance to motilin. Gastroenterology 120: 337-345, 2001.

10. Nakazato M, Murakami N, Date Y, et al: A role for ghrelin in the central regulation of feeding. Nature 409: 194-198, 2001.

11. Wren AM, Small CJ, Ward HL, et al: The novel hypothalamic peptide ghrelin stimulates food intake and growth hormone secretion. Endocrinology 141: 4325-4328, 2000.

12. Inui A: Ghrelin: an orexigenic and somatotrophic signal from the stomach. Nat Rev Neurosci 2: 551-560, 2001.

13. An W, Li Y, Xu G, et al: Modulation of ghrelin $O$-acyltransferase expression in pancreatic islets. Cell Physiol Biochem 26: 707-716, 2010.

14. Murray CD, Martin NM, Patterson M, et al: Ghrelin enhances gastric emptying in diabetic gastroparesis: a double blind, placebo controlled, crossover study. Gut 54: 1693-1698, 2005.

15. Tack J, Depoortere I, Bisschops R, Verbeke K, Janssens J and Peeters T: Influence of ghrelin on gastric emptying and mealrelated symptoms in idiopathic gastroparesis. Aliment Pharmacol Ther 22: 847-853, 2005

16. Tack J, Depoortere I, Bisschops R, et al: Influence of ghrelin on interdigestive gastrointestinal motility in humans. Gut 55: 327-333, 2006.

17. Mori M, Suzuki H, Masaoka T, et al: Intravenous ghrelin administration enhances gastric acid secretion - evaluation using wireless $\mathrm{pH}$ capsule. Aliment Pharmacol Ther 24: 96-103, 2006.

18. Masuda Y, Tanaka T, Inomata N, et al: Ghrelin stimulates gastric acid secretion and motility in rats. Biochem Biophys Res Commun 276: 905-908, 2000.

19. Castaneda TR, Tong J, Datta R, Culler M and Tschop MH: Ghrelin in the regulation of body weight and metabolism. Front Neuroendocrinol 31: 44-60, 2010.

20. Fetissov SO, Laviano A, Kalra S and Inui A: Update on ghrelin Int J Pept 2010: 963501, 2010.
21. Asakawa A, Inui A, Kaga T, et al: A role of ghrelin in neuroendocrine and behavioral responses to stress in mice. Neuroendocrinology 74: 143-147, 2001.

22. Hotta M, Ohwada R, Akamizu T, Shibasaki T, Takano K and Kangawa K: Ghrelin increases hunger and food intake in patients with restricting-type anorexia nervosa: a pilot study. Endocr J 56: $1119-1128,2009$.

23. Akamizu T, Iwakura $\mathrm{H}$, Ariyasu $\mathrm{H}$, et al: Effects of ghrelin treatment on patients undergoing total hip replacement for osteoarthritis: different outcomes from studies in patients with cardiac and pulmonary cachexia. J Am Geriatr Soc 56: 2363-2365, 2008.

24. Miki K, Maekura R, Nagaya N, et al: Ghrelin treatment of cachectic patients with chronic obstructive pulmonary disease: a multicenter, randomized, double-blind, placebo-controlled trial. PloS One 7: e35708, 2012.

25. Akamizu T, Iwakura $\mathrm{H}$, Ariyasu $\mathrm{H}$, et al: Repeated administration of ghrelin to patients with functional dyspepsia: its effects on food intake and appetite. Eur J Endocrinol 158: 491-498, 2008.

26. Wo JM, Ejskjaer N, Hellstrom PM, et al: Randomised clinical trial: ghrelin agonist TZP-101 relieves gastroparesis associated with severe nausea and vomiting - randomised clinical study subset data. Aliment Pharmacol Ther 33: 679-688, 2011.

27. Drossman DA and Dumitrascu DL: Rome III: New standard for functional gastrointestinal disorders. J Gastrointestin Liver Dis 15: 237-241, 2006.

28. Miwa H: Why dyspepsia can occur without organic disease: pathogenesis and management of functional dyspepsia. $J$ Gastroenterol 47: 862-871,2012.

29. Miwa $\mathrm{H}$ : Life style in persons with functional gastrointestinal disorders - large-scale internet survey of lifestyle in Japan. Neurogastroenterol Motil 24: 464-471, e217, 2012.

30. Norton GR, Norton PJ, Asmundson GJ, Thompson LA and Larsen DK: Neurotic butterflies in my stomach: the role of anxiety, anxiety sensitivity and depression in functional gastrointestinal disorders. J Psychosom Res 47: 233-240, 1999.

31. Khoo J, Rayner CK, Feinle-Bisset C, Jones KL and Horowitz M: Gastrointestinal hormonal dysfunction in gastroparesis and functional dyspepsia. Neurogastroenterol Motil 22: 1270-1278, 2010.

32. Quartero AO, de Wit NJ, Lodder AC, Numans ME, Smout AJ and Hoes AW: Disturbed solid-phase gastric emptying in functional dyspepsia: a meta-analysis. Dig Dis Sci 43: 2028-2033, 1998.

33. Geeraerts B, Van Oudenhove L, Fischler B, et al: Influence of abuse history on gastric sensorimotor function in functional dyspepsia. Neurogastroenterol Motil 21: 33-41, 2009.

34. Holtmann G, Siffert W, Haag S, et al: G-protein beta 3 subunit $825 \mathrm{CC}$ genotype is associated with unexplained (functional) dyspepsia. Gastroenterology 126: 971-979, 2004.

35. Toyoshima F, Oshima T, Nakajima S, et al: Serotonin transporter gene polymorphism may be associated with functional dyspepsia in a Japanese population. BMC Med Genet 12: 88, 2011.

36. Mearin F, Perez-Oliveras M, Perello A, et al: Dyspepsia and irritable bowel syndrome after a Salmonella gastroenteritis outbreak: one-year follow-up cohort study. Gastroenterology 129: 98-104, 2005.

37. Drossman DA: The functional gastrointestinal disorders and the Rome III process. Gastroenterology 130: 1377-1390, 2006.

38. Danesh J, Lawrence M, Murphy M, Roberts S and Collins R: Systematic review of the epidemiological evidence on Helicobacter pylori infection and nonulcer or uninvestigated dyspepsia. Arch Intern Med 160: 1192-1198, 2000.

39. Kawamura A, Adachi K, Takashima T, et al: Prevalence of functional dyspepsia and its relationship with Helicobacter pylori infection in a Japanese population. J Gastroenterol Hepatol 16: 384-388, 2001

40. Thumshirn M, Camilleri M, Saslow SB, Williams DE, Burton DD and Hanson RB: Gastric accommodation in non-ulcer dyspepsia and the roles of Helicobacter pylori infection and vagal function. Gut 44: 55-64, 1999

41. Sarnelli G, Cuomo R, Janssens J and Tack J: Symptom patterns and pathophysiological mechanisms in dyspeptic patients with and without Helicobacter pylori. Dig Dis Sci 48: 2229-2236, 2003.

42. Savarino E, Zentilin P, Dulbecco P, Malesci A and Savarino V: The role of Acid in functional dyspepsia. Am J Gastroenterol 106: 1168-1169, 2011.

43. Jin X and Li YM: Systematic review and meta-analysis from Chinese literature: the association between Helicobacter pylori eradication and improvement of functional dyspepsia. Helicobacter 12: 541-546, 2007. 
44. Moayyedi P, Soo S, Deeks J, et al: Eradication of Helicobacter pylori for non-ulcer dyspepsia. Cochrane Database Syst Rev 2006: CD002096, 2006.

45. Moayyedi P: Helicobacter pylori eradication for functional dyspepsia: what are we treating?: comment on 'Helicobacter pylori eradication in functional dyspepsia'. Arch Intern Med 171: 1936-1937, 2011.

46. Suzuki H and Moayyedi P: Helicobacter pylori infection in functional dyspepsia. Nat Rev Gastroenterol Hepatol 10: 168-174, 2013.

47. Sugano K: Should we still subcategorize Helicobacter pyloriassociated dyspepsia as functional disease? J Neurogastroenterol Motil 17: 366-371, 2011.

48. Tack J, Caenepeel P, Fischler B, Piessevaux H and Janssens J: Symptoms associated with hypersensitivity to gastric distention in functional dyspepsia. Gastroenterology 121: 526-535, 2001.

49. Boeckxstaens GE, Rumessen JJ, de Wit L, Tytgat GN and Vanderwinden JM: Abnormal distribution of the interstitial cells of cajal in an adult patient with pseudo-obstruction and megaduodenum. Am J Gastroenterol 97: 2120-2126, 2002.

50. Rhee PL, Kim YH, Son HJ, et al: Evaluation of individual symptoms cannot predict presence of gastric hypersensitivity in functional dyspepsia. Dig Dis Sci 45: 1680-1684, 2000.

51. Chrousos GP: Regulation and dysregulation of the hypothalamicpituitary-adrenal axis. The corticotropin-releasing hormone perspective. Endocrinol Metab Clin North Am 21: 833-858, 1992.

52. Lamberts SW, Verleun T, Oosterom R, de Jong $\mathrm{F}$ and Hackeng WH: Corticotropin-releasing factor (ovine) and vasopressin exert a synergistic effect on adrenocorticotropin release in man. J Clin Endocrinol Metab 58: 298-303, 1984.

53. Vale W, Spiess J, Rivier C and Rivier J: Characterization of a 41-residue ovine hypothalamic peptide that stimulates secretion of corticotropin and beta-endorphin. Science 213: 1394-1397, 1981.

54. Vaughan J, Donaldson C, Bittencourt J, et al: Urocortin, a mammalian neuropeptide related to fish urotensin I and to corticotropin-releasing factor. Nature 378: 287-292, 1995

55. Bale TL and Vale WW: CRF and CRF receptors: role in stress responsivity and other behaviors. Annu Rev Pharmacol Toxicol 44: 525-557, 2004

56. Ataka K, Kuge T, Fujino K, Takahashi T and Fujimiya M: Wood creosote prevents CRF-induced motility via 5-HT3 receptors in proximal and 5-HT4 receptors in distal colon in rats. Auton Neurosci 133: 136-145, 2007.

57. Martinez V, Rivier J, Wang L and Tache Y: Central injection of a new corticotropin-releasing factor (CRF) antagonist, astressin, blocks CRF- and stress-related alterations of gastric and colonic motor function. J Pharmacol Exp Ther 280: 754-760, 1997.

58. Tache Y, Martinez V, Million M and Wang L: Stress and the gastrointestinal tract III. Stress-related alterations of gut motor function: role of brain corticotropin-releasing factor receptors. Am J Physiol Gastrointest Liver Physiol 280: G173-G177, 2001.

59. O'Mahony SM, Marchesi JR, Scully P, et al: Early life stress alters behavior, immunity, and microbiota in rats: implications for irritable bowel syndrome and psychiatric illnesses. Biol Psychiatry 65: 263-267, 2009.

60. Brevet M, Kojima H, Asakawa A, et al: Chronic foot-shock stress potentiates the influx of bone marrow-derived microglia into hippocampus. J Neurosci Res 88: 1890-1897, 2010.

61. Sengupta JN: Visceral pain: the neurophysiological mechanism. Handb Exp Pharmacol 194: 31-74, 2009.

62. Shindo T, Futagami S, Hiratsuka T, et al: Comparison of gastric emptying and plasma ghrelin levels in patients with functional dyspepsia and non-erosive reflux disease. Digestion 79: 65-72, 2009.

63. Lee KJ, Cha DY, Cheon SJ, Yeo M and Cho SW: Plasma ghrelin levels and their relationship with gastric emptying in patients with dysmotility-like functional dyspepsia. Digestion 80: 58-63, 2009.

64. Sarnelli G, Caenepeel P, Geypens B, Janssens J and Tack J: Symptoms associated with impaired gastric emptying of solids and liquids in functional dyspepsia. Am J Gastroenterol 98 783-788, 2003

65. Asakawa A, Inui A, Ueno N, Makino S, Fujino MA and Kasuga M: Urocortin reduces food intake and gastric emptying in lean and ob/ob obese mice. Gastroenterology 116: 1287-1292, 1999.

66. Fujino K, Inui A, Asakawa A, Kihara N, Fujimura M and Fujimiya M: Ghrelin induces fasted motor activity of the gastrointestinal tract in conscious fed rats. J Physiol 550: 227-240, 2003
67. Fujimiya M, Itoh E, Kihara N, Yamamoto I, Fujimura M and Inui A: Neuropeptide Y induces fasted pattern of duodenal motility via $Y(2)$ receptors in conscious fed rats. Am J Physiol Gastrointest Liver Physiol 278: G32-G38, 2000.

68. Fujimiya M, Asakawa A, Ataka K, Kato I and Inui A: Different effects of ghrelin, des-acyl ghrelin and obestatin on gastroduodenal motility in conscious rats. World J Gastroenterol 14: 6318-6326, 2008.

69. Peeters TL: Central and peripheral mechanisms by which ghrelin regulates gut motility. J Physiol Pharmacol 54 (Suppl 4): S95-S103, 2003.

70. Venkova K and Greenwood-Van Meerveld B: Application of ghrelin to gastrointestinal diseases. Curr Opin Investig Drugs 9: 1103-1107, 2008

71. Asakawa A, Inui A, Fujimiya M, et al: Stomach regulates energy balance via acylated ghrelin and desacyl ghrelin. Gut 54: 18-24, 2005.

72. Ariyasu H, Takaya K, Iwakura H, et al: Transgenic mice overexpressing des-acyl ghrelin show small phenotype. Endocrinology 146: 355-364, 2005.

73. Chen CY, Chao Y, Chang FY, Chien EJ, Lee SD and Doong ML: Intracisternal des-acyl ghrelin inhibits food intake and nonnutrient gastric emptying in conscious rats. Int J Mol Med 16: 695-699, 2005.

74. Chen CY, Inui A, Asakawa A, et al: Des-acyl ghrelin acts by CRF type 2 receptors to disrupt fasted stomach motility in conscious rats. Gastroenterology 129: 8-25, 2005.

75. Inhoff T, Monnikes H, Noetzel S, et al: Desacyl ghrelin inhibits the orexigenic effect of peripherally injected ghrelin in rats. Peptides 29: 2159-2168, 2008.

76. Qader SS, Hakanson R, Rehfeld JF, Lundquist I and Salehi A: Proghrelin-derived peptides influence the secretion of insulin, glucagon, pancreatic polypeptide and somatostatin: a study on isolated islets from mouse and rat pancreas. Regul Pept 146: 230-237, 2008.

77. Banks WA, Tschop M, Robinson SM and Heiman ML: Extent and direction of ghrelin transport across the blood-brain barrier is determined by its unique primary structure. J Pharmacol Exp Ther 302: 822-827, 2002.

78. Martinez V, Barquist E, Rivier J and Tache Y: Central CRF inhibits gastric emptying of a nutrient solid meal in rats: the role of CRF2 receptors. Am J Physiol 274: G965-G970, 1998.

79. Million M, Maillot C, Saunders P, Rivier J, Vale W and Tache Y: Human urocortin II, a new CRF-related peptide, displays selective $\mathrm{CRF}(2)$-mediated action on gastric transit in rats. Am J Physiol Gastrointest Liver Physiol 282: G34-G40, 2002.

80. Kihara N, Fujimura M, Yamamoto I, Itoh E, Inui $A$ and Fujimiya M: Effects of central and peripheral urocortin on fed and fasted gastroduodenal motor activity in conscious rats. Am J Physiol Gastrointest Liver Physiol 280: G406-G419, 2001.

81. Zhang JV, Ren PG, Avsian-Kretchmer O, et al: Obestatin, a peptide encoded by the ghrelin gene, opposes ghrelin's effects on food intake. Science 310: 996-999, 2005.

82. Chartrel N, Alvear-Perez R, Leprince J, et al: Comment on 'Obestatin, a peptide encoded by the ghrelin gene, opposes ghrelin's effects on food intake'. Science 315: 766, 2007.

83. Holst B, Egerod KL, Schild E, et al: GPR39 signaling is stimulated by zinc ions but not by obestatin. Endocrinology 148: 13-20, 2007.

84. Tremblay F, Perreault M, Klaman LD, Tobin JF, Smith E and Gimeno RE: Normal food intake and body weight in mice lacking the $\mathrm{G}$ protein-coupled receptor GPR39. Endocrinology 148: 501-506, 2007.

85. Bassil AK, Haglund Y, Brown J, et al: Little or no ability of obestatin to interact with ghrelin or modify motility in the rat gastrointestinal tract. Br J Pharmacol 150: 58-64, 2007.

86. Bresciani E, Rapetti D, Dona F, et al: Obestatin inhibits feeding but does not modulate $\mathrm{GH}$ and corticosterone secretion in the rat. J Endocrinol Invest 29: RC16-RC18, 2006.

87. Ataka K, Inui A, Asakawa A, Kato I and Fujimiya M: Obestatin inhibits motor activity in the antrum and duodenum in the fed state of conscious rats. Am J Physiol Gastrointest Liver Physiol 294: G1210-G1218, 2008.

88. Takamori K, Mizuta Y, Takeshima F, et al: Relation among plasma ghrelin level, gastric emptying, and psychologic condition in patients with functional dyspepsia. J Clin Gastroenterol 41: 477-483, 2007

89. Nishizawa T, Suzuki H, Nomoto Y, et al: Enhanced plasma ghrelin levels in patients with functional dyspepsia. Aliment Pharmacol Ther 24 (Suppl 4): S104-S110, 2006. 
90. Shinomiya T, Fukunaga M, Akamizu T, et al: Plasma acylated ghrelin levels correlate with subjective symptoms of functional dyspepsia in female patients. Scand J Gastroenterol 40: 648-653, 2005.

91. Kim YS, Lee JS, Lee TH, et al: Plasma levels of acylated ghrelin in patients with functional dyspepsia. World J Gastroenterol 18: 2231-2237, 2012.

92. Taniguchi $\mathrm{H}$, Ariga $\mathrm{H}$, Zheng J, et al: Endogenous ghrelin and 5-HT regulate interdigestive gastrointestinal contractions in conscious rats. Am J Physiol Gastrointest Liver Physiol 295: G403-G411, 2008.

93. Tack J, Janssen P, Masaoka T, Farre R and Van Oudenhove L: Efficacy of buspirone, a fundus-relaxing drug, in patients with functional dyspepsia. Clin Gastroenterol Hepatol 10: 1239-1245, 2012.

94. Seto Y, Yoshida N and Kaneko H: Effects of mosapride citrate, a 5-HT4-receptor agonist, on gastric distension-induced visceromotor response in conscious rats. J Pharmacol Sci 116: 47-53, 2011.
95. Lee JW, Sung KW, Lee OY, Lee SE and Sohn CI: The effects of 5-HT4 receptor agonist, mosapride citrate, on visceral hypersensitivity in a rat model. Dig Dis Sci 57: 1517-1524, 2012.

96. Fujitsuka N, Asakawa A, Amitani H, Hattori T and Inui A: Efficacy of ghrelin in cancer cachexia: clinical trials and a novel treatment by rikkunshito. Crit Rev Oncog 17: 277-284, 2012.

97. Arai M, Matsumura T, Tsuchiya N, et al: Rikkunshito improves the symptoms in patients with functional dyspepsia, accompanied by an increase in the level of plasma ghrelin. Hepatogastroenterology 59: 62-66, 2012.

98. Takeda H, Sadakane C, Hattori T, et al: Rikkunshito, an herbal medicine, suppresses cisplatin-induced anorexia in rats via 5-HT2 receptor antagonism. Gastroenterology 134: 2004-2013, 2008.

99. Matsumura T, Arai M, Yonemitsu Y, et al: The traditional Japanese medicine Rikkunshito increases the plasma level of ghrelin in humans and mice. J Gastroenterol 45: 300-307, 2010 . 